\title{
PRELIMINARY ESTIMATES OF BUILDING COST AND THE LOWEST EVALUATED TENDER
}

\author{
Harriet K Eliufoo \\ School of Construction Economics \\ Ardhi University, P.O.Box 35176 \\ DAR ES SALAAM: [heliufoo@yahoo.com]
}

\begin{abstract}
The paper has investigated and established to what extent are preliminary estimates of building costs close to the lowest evaluated tender and how geographical proximity influences the variance between preliminary estimate and the lowest evaluated tender.

A multiple case study constituting 43 building projects in Tanzania were statistically analysed covering a period from 1995- 1999. Findings reveal a significant variance exists between the quantity surveyor's preliminary estimate figure and the lowest evaluated tender; and that the variance between the quantity surveyor's figure and the bidder is small when the proposed building project is geographically closer to the quantity surveyor's base. Analysis of variance (one way) has shown geographical distance has a statistical significance on the variance between the preliminary estimates and the lowest evaluated tender.
\end{abstract}

The study has established that the object of preliminary estimates in building costs, that of making the client aware of his financial obligations at early stages of a building project are not met fully.

Keywords: Preliminary estimates, prices, building projects, Tanzania, tender bid, quantity surveyor

\section{INTRODUCTION}

Preliminary estimates are prepared by a consultant quantity surveyor and in some countries by a cost engineer to establish the probable cost of a future building project prior to production of detailed designs. The purpose of the estimates is to acquaint the building client to likely financial implications of his requirements. As applied in cost planning of buildings, preliminary estimates, identifies imbalances of costs among various building elements and forms a basis for budgeting and cost control. It is one of the most complex and difficult task facing the quantity surveying or cost engineering profession (Shen et al, 2001) as at the early stages of a building project, though design information is limited, the Quantity surveyor has to deploy enormous data to convert it to cost information.

Financial information is key to a building client at inception stages of a building project, and it is expected to be realistic, reliable and prepares the client for financial obligations of an intended building project. Dent, (1974) had described the process of monitoring costs at design stage so as for the tender figure not to deviate from the preliminary estimate as cost planning; it is a process, he describes as giving the client value for money.
However, despite acknowledging the need for reliability of this estimate from the quantity surveyor, the figure, which the client eventually pays for, is the lowest evaluated tender figure.

Taking this figure to reflect market price of the intended development, one would expect, the two figures, that of the Quantity surveyor and the lowest evaluated tender to be close within an acceptable margin.

It is also true that realistic preliminary estimates are an outcome of technical and market information of which they are based. Although, there is no universal range for all in the construction industry, it is however justifiable for construction firms to thrive for a benchmark, and have an acceptable range between the consultant's preliminary estimates and the lowest evaluated tender.

Adopting the definition of cost planning as explained by various authors, Dent (1974), Seeley, (1981), Flanagan and Tate (1997) and Smith and Love (2000), that it comprises a system of monitoring building costs at design stage to ensure that the tender does not exceed the preliminary estimates; it hence follows that the client's expectations are, for the tender figure and the quantity surveyor's estimate to be close, if not exact. 
It is from this background that the paper investigates to what extent the client's expectations are met, or how value for money is delivered to the customer.

\section{Main Objective}

Investigate and establish to what extent are the Quantity surveyor's preliminary estimates for building costs close to the lowest evaluated tender.

\section{Specific objective}

Investigate how is spatial location of a building project reflected in the variance between the Quantity surveyor's preliminary estimates and the lowest evaluated tender.

\section{LITERATURE REVIEW}

The quantity surveyor is specially equipped to provide estimates of initial costs for construction projects, since he is a professional cost consultant by training and experience (Seeley, 1976; Dent, 1974). Methods for establishing preliminary estimates go as far back as early 1930's which include methods such as: unit, cube, superficial, storey-enclosure, approximate quantities and elemental cost analysis. Except for the superficial floor area method, over time most of these methods have become obsolete (Mongi, 1999; Cheung and Skitmore, 2006). Cheung and Skitmore (2006) when testing the performance of the single rate methods of estimating established the widely used superficial floor area method significantly under-performs in terms of consistency for office buildings and private housing while the storey enclosure method showed better prospects of performing in private housing. It is also noted that the complexity and timeconsuming task of producing pre-tender cost estimates have attracted efforts to deploy information technology as a solution. Shen et al.
(2001) cites those that had developed knowledge based systems performing various complex tasks such as pre-tender cost estimates and preparation of cost estimates for a building project before any architectural or engineering design is developed; techniques using regression analysis, simulations and neural networks are now used in the pre- design cost estimates (Sonmez, 2004). Ling and See Boo (2001) on the other hand when investigated 41 quantity surveying firms in Singapore on how improvement of estimating accuracy could be achieved, zeroed down to the quality and adequacy of information availed during the preparation of estimates.

\section{Preliminary estimates preparation as a business process}

Winch and Carr (2001) have emphasized the significance of process mapping in any construction process and acknowledged the fact that the final product that the customer buys constitutes an embodiment of both information and material. Subsequent to this view, mapping the process of these constituents becomes essential in meeting the customer's requirements. At early stages of a building project in addition to the building design, the customer buys cost information that reflects the financial obligations of an intended building project. Preliminary estimates are hence done at this initial design stages albeit limitation of information. Such estimates are not stagnant but evolve, as more information of the building project is available and form the bases of its cost plan. Such evolution is made possible as project key actors avail the Quantity surveyor with more information at this phase. Table 1 illustrates how interaction of these key actors transforms cost information through various stages of the design phase to tender action.

Table 1: Key actors during the cost planning stage of a building project
Client action
Architect and engineer's action
Quantity surveyor's action
I Client's requirements Brief preparation
II Client's clarifies Forms of construction and requirements from brief
layout development
Sketch plans production
III Client confirms on sketch Updating Client's requirements plans or confirmation Initial preliminary estimates preparation
Preliminary estimates review and update
Preliminary estimates update and cost plans preparation
IV Limited action
V Limited action
VI Tender action
Design according to cost plan
Detail design development
Limited action
Cost checks done for conformity of design to cost targets
Bills of Quantities preparation
Evaluation and identification of the lowest evaluated tender


The evolution of preliminary estimates to cost plans is an essential aspect of cost control during the design phase of a building project, as it involves establishment of cost targets for building elements; and confining design of these elements to the set

targets; a procedure identified as, "designing to a cost" (Seeley, 1976; Bathurst and Butler, 1980). Preliminary estimates hence form a base for cost targets that control cost of the design; hence compelling an architect to develop the building design conforming to these cost targets and subsequently meet a set cost limit or budget. It is hence justifiable to expect that if the design has developed according to the confines of the set cost targets, the outcome of tender action should not significantly differ from the preliminary estimates. Figure I illustrates how such a process is envisioned. The difference between preliminary estimates and the tender bid is hence optimally expected to be within reasonable limit. To what extent such envision is visualised, is being addressed in this paper.

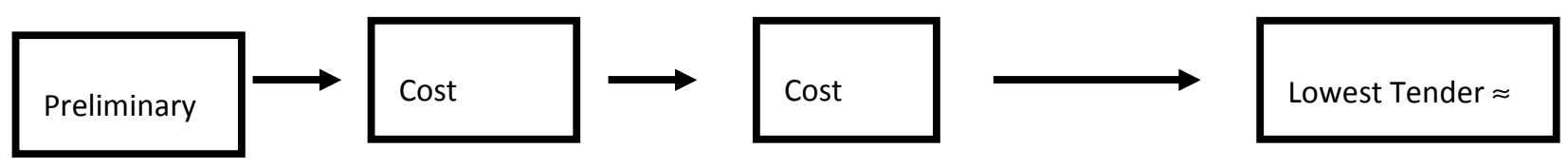

\section{COST PLANNING}

Figure I: The evolution of preliminary estimates during design phase

\section{Challenges in the preparation of a preliminary estimate}

A variety of factors influence the cost of a building project. They include: design variables such as a building's total height, width, floor to ceiling height, proportion of circulation space, type of construction, methods of construction (e.g. in-situ or prefabricated, framed structure or load bearing walls). Specifications equally influence the cost of a building. Other factors are: land terrain, type of ground: rocky, made-up or swampy land; site location like when construction of a building is at a congested or a remote site or where services such as electricity, water, telecommunication and roads are difficult to access. All these, influence the cost of a building project. Factors identified though not exhaustive, implicate that a quantity surveyor has to manage enormous amount of data, coupled with reasonable assumptions, in the preparation of an estimate. Ashworth (1999) in characterising cost data for buildings asserted during the early stages of the design process as the data more related to function and design while at the later stages of the design process related to quantity and specifications.

Another distinct challenge encountered by quantity surveyors in the course of preparing preliminary estimates is the reliance for a substantial amount of information on historical cost that is inherently inhibitive (Ferry et al, 1991).

\section{METHODOLOGY}

An "information rich" approach that can provide adequate information for questions pursued by an investigation (Patton, 1987) or what Bless and Higson- Smith (1995) referred to as judgmental sampling was used in sourcing information. 43 building projects in the period 1995 - 1999 were used as sample for analysis. This sample was randomly sourced from a list of practicing quantity surveying firms in the Tanzanian construction industry. Five years was taken as the author views as an adequate period for one to make a reasonable analysis of existence of a particular phenomenon.

Figure II shows a map of the republic of Tanzania and its regions illustrating the wide geographical spectrum of the study's sample. Arrows have been used to emphasize the geographical distance of building projects and the consultant's base, which is Dar es Salaam. Sample projects are widely spread, some being in the North Western part of Tanzania like Mwanza, others in the North East like those in Arusha, Kilimanjaro, and Tanga; and some, West like Tabora, South like Iringa and Mtwara and a majority being in Dar es Salaam and Morogoro regions. 


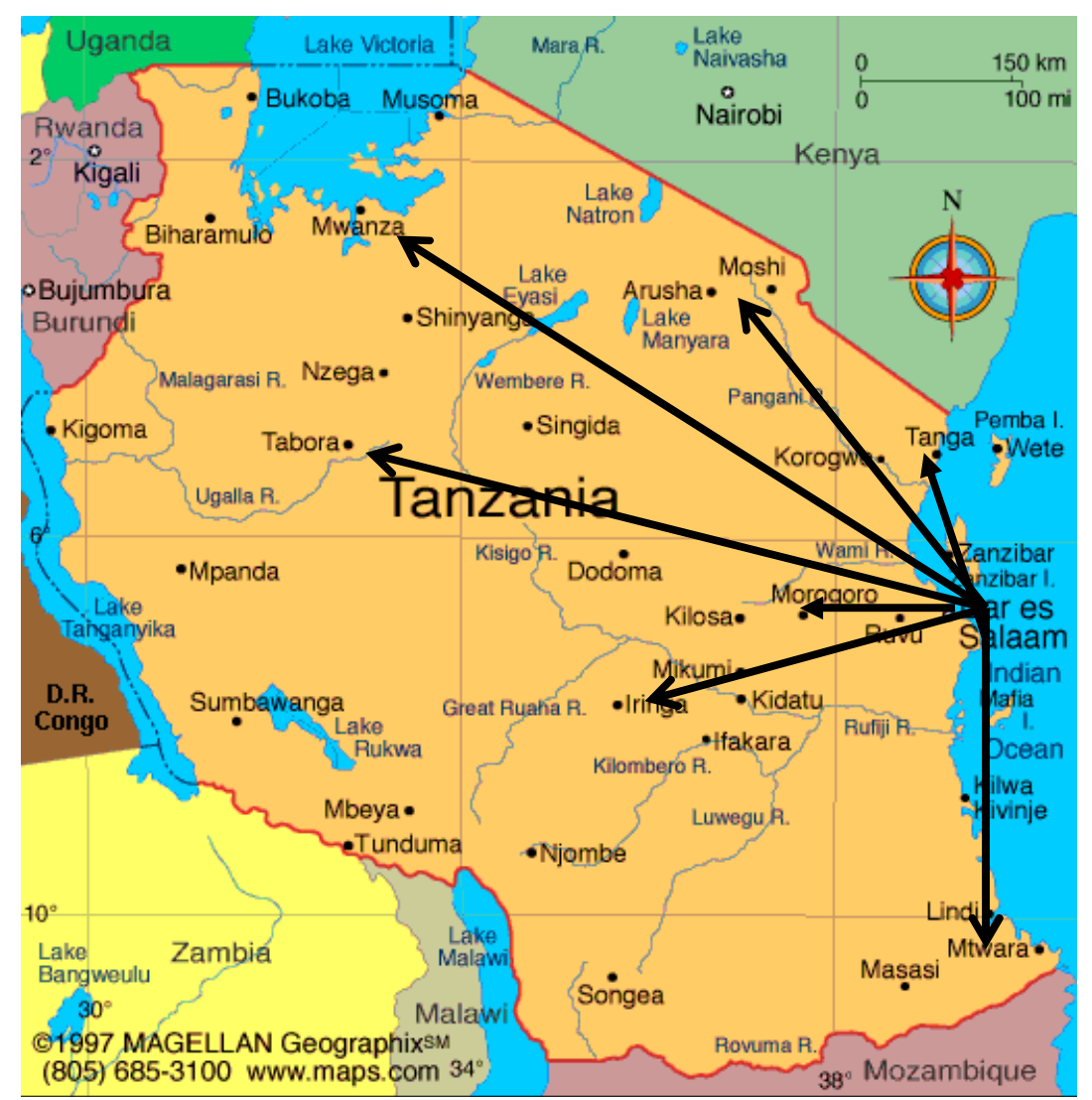

Figure II: Map of Tanzania and its regions (Source: MAGELLAN Geographix, 1997)

\section{Standard deviation as a measure of central tendency}

Essentially standard deviation measures how widely spread values are in a data set. A large standard deviation indicates that data points are far from the mean and a small standard deviation indicates a closer cluster to the mean. Standard deviations may also serve as a measure of uncertainty; for instance in physical science when used to indicate the precision of a set of measurements. The significance of understanding the standard deviation for a sample is hence in appreciating how much variation there is from the "average". In this paper, standard deviation has been used for the typical purpose of establishing the variance from the mean of the sample, and specifically investigate how spatial location influences such variance; a question pursued by the specific objectives of this paper.

\section{Data collection and analysis}

Table 3 provides basis of analysis of the sample. The data has two sets of information, basic information such as, year of award and geographical location of project; and the other set that provides amounts for the preliminary estimates as prepared by a Quantity Surveyor and the tendered amount by the lowest evaluated tender.

\section{The analysis was in stages:}

i. An initial stage of making a comparison between the Quantity Surveyor's preliminary estimate and the tender figure, where the percentage difference was computed i.e. establishment of the variance

ii. A subsequent stage that established the mean of the variance between the two figures and how widely spread the variance is, in relation to the mean, i.e. the standard deviation and

iii. A final stage that established the variance from the mean for projects done in the City of Dar es Salaam only.

The final analysis was prompted by the fact that as over $80 \%$ of registered Quantity Surveying firms in Tanzania are based in its largest City, Dar es Salaam, the selection of respondents resulted to all being based in Dar es Salaam; an investigation was done in retrospect to explore how geographical vicinity of a building project site in relation to a Quantity surveying firm's location is reflected in preliminary estimates of a building project. The aim was to establish whether building projects in close vicinity with the Quantity surveyor's office, enables the Quantity surveyor to have more information regarding site and local conditions that influence the 
preliminary estimates. Taking a lowest evaluated bid, as reflecting a market price for an intended development, one expects to have estimates that are closer to the market price when the Quantity surveyor's firm is physically located in the same market of the proposed development. Table 2 illustrates regional distances in kilometres of sample projects from the quantity surveyors' base, supplemented by an illustration in Figure II. Geographical distances from Dar es Salaam city have been categorized into four categories, A, B, C and $\mathrm{D}$ depending on the distance as shown in Table 2.

Figure III and IV are normal standard distribution of the sample whereby the $\mathrm{x}$-values are converted to $\mathrm{z}$ values; with the z-value for each entry given by:
$\mathrm{Z}=\quad$ Variable - Mean

Standard deviation

Whereby for the sample:

- $\quad$ Variable $=$ Variation mean

- $\quad$ Mean $=$ Variation

The significance of the z-score is that it standardizes a person's score with reference to the rest of the score in a group, something that the normal distribution curve with $\mathrm{x}$-values does not; hence it expresses a particular score in terms of how many standard deviations it is away from the mean of the set of scores. Figure III and IV thus show, a substantial proportion of quantity surveyor's preliminary estimates are above the mean; with a relatively higher proportion, for construction projects in Dar es Salaam (refer figure IV).

Table 2: Distances of project samples from Dar es Salaam city

\begin{tabular}{|lc|lr|lr|l|}
\hline \multicolumn{2}{|l|}{ Category A $>1000 \mathrm{Km}$} & Category B: 300 to $1000 \mathrm{Km}$ & Category C: 100 to $300 \mathrm{Km}$ & Category D: $<100 \mathrm{Km}$ \\
\hline Tabora 1039 & Tanga & 354 & Morogoro 196 & Dar es Salaam \\
Mwanza & 1164 & Iringa & 501 & & \\
& & Kilimanjaro & 562 & & \\
& Mtwara & 565 & & \\
& Arusha & 647 & & \\
\hline
\end{tabular}

Table 3: Variance between consultant's preliminary estimate and lowest evaluated tender (all regions)

\begin{tabular}{|c|c|c|c|c|c|c|}
\hline Project & Year & Category & $\begin{array}{l}\text { Preliminary } \\
\text { cost } \\
\text { estimates }\end{array}$ & $\begin{array}{l}\text { Lowest } \\
\text { evaluated } \\
\text { tender }\end{array}$ & $\begin{array}{l}\text { Variation } \\
(\$)\end{array}$ & $\begin{array}{l}\text { Variat } \\
(\%)\end{array}$ \\
\hline \multirow[t]{18}{*}{ (a) } & (b) & (c) & (d) & (e) & (f) & (g) \\
\hline & & & US \$ & US \$ & US \$ & \\
\hline & 1992 & $\mathrm{D}$ & 95618 & 83402 & 12215 & 12,8 \\
\hline & 1994 & $\mathrm{D}$ & 231076 & 206915 & 24161 & 10,5 \\
\hline & 1994 & $\mathrm{D}$ & 796813 & 743085 & 53728 & 6,7 \\
\hline & 1994 & $\mathrm{C}$ & 106825 & 97113 & 9711 & 9,1 \\
\hline & 1994 & $\mathrm{D}$ & 2382678 & 2175961 & 206716 & 8,7 \\
\hline & 1995 & $\mathrm{~A}$ & 390263 & 430279 & 40016 & $-10,3$ \\
\hline & 1995 & $\mathrm{D}$ & 10249 & 9317 & 932 & 9,1 \\
\hline & 1995 & $\mathrm{C}$ & 12671 & 11732 & 939 & 7,4 \\
\hline & 1995 & $\mathrm{D}$ & 119261 & 108815 & 10446 & 8,8 \\
\hline & 1995 & $\mathrm{D}$ & 612988 & 490040 & 122948 & 20,1 \\
\hline & 1995 & $\mathrm{D}$ & 912279 & 821873 & 90406 & 9,9 \\
\hline & 1995 & $\mathrm{D}$ & 13000398 & 11872510 & 1127888 & 8,7 \\
\hline & 1996 & $\mathrm{D}$ & 741832 & 693301 & 48531 & 6,5 \\
\hline & 1996 & $\mathrm{D}$ & 45423 & 41672 & 3751 & 8,3 \\
\hline & 1996 & $\mathrm{D}$ & 20504 & 18725 & 1779 & 8,7 \\
\hline & 1996 & $\mathrm{D}$ & 226032 & 203632 & 22400 & 9,9 \\
\hline
\end{tabular}




\begin{tabular}{|c|c|c|c|c|c|}
\hline 1996 & B & 1111124 & 1011952 & 99171 & 8,9 \\
\hline 1997 & B & 306773 & 278884 & 27888 & 9,1 \\
\hline 1997 & B & 129184 & 117976 & 11208 & 8,7 \\
\hline 1997 & B & 9080 & 8331 & 750 & 8,3 \\
\hline 1997 & $\mathrm{D}$ & 15469 & 14257 & 1212 & 7,8 \\
\hline 1997 & $\mathrm{D}$ & 137946 & 126672 & 11274 & 8,2 \\
\hline 1997 & B & 908 & 825 & 83 & 9,1 \\
\hline 1997 & A & 97957 & 87259 & 10698 & 10,9 \\
\hline 1997 & B & 476822 & 437451 & 39371 & 8,3 \\
\hline 1997 & $\mathrm{C}$ & 102602 & 96185 & 6417 & 6,3 \\
\hline 1997 & $\mathrm{C}$ & 83705 & 76096 & 7610 & 9,1 \\
\hline 1997 & $\mathrm{C}$ & 190238 & 175334 & 14903 & 7,8 \\
\hline 1998 & B & 33842 & 30906 & 2936 & 8,7 \\
\hline 1998 & $\mathrm{D}$ & 14900398 & 13545817 & 1354582 & 9,1 \\
\hline 1998 & B & 19326 & 17601 & 1725 & 8,9 \\
\hline 1999 & $\mathrm{D}$ & 3715367 & 3396131 & 319236 & 8,6 \\
\hline 1999 & $\mathrm{D}$ & 13657061 & 12645427 & 1011635 & 7,4 \\
\hline 1999 & $\mathrm{D}$ & 501355 & 455777 & 45578 & 9,1 \\
\hline 1999 & $\mathrm{D}$ & 61851 & 56692 & 5159 & 8,3 \\
\hline 1999 & $\mathrm{D}$ & 6398 & 5924 & 474 & 7,4 \\
\hline 1999 & $\mathrm{D}$ & 672797 & 625858 & 46939 & 7,0 \\
\hline 1999 & $\mathrm{D}$ & 908 & 825 & 83 & 9,1 \\
\hline 1999 & $\mathrm{D}$ & 140434 & 128250 & 12184 & 8,7 \\
\hline 1999 & $\mathrm{D}$ & 627714 & 694643 & 66929 & $-10,7$ \\
\hline 1999 & B & 135233 & 150259 & 15026 & $-11,1$ \\
\hline 1999 & A & 107855 & 119177 & 11322 & $-10,5$ \\
\hline 1999 & $\mathrm{C}$ & 125535 & 127421 & 1886 & $-1,5$ \\
\hline & & & & $\begin{array}{l}\text { Average } \\
\text { Std Dev }\end{array}$ & $\begin{array}{l}6,9 \\
6,2\end{array}$ \\
\hline
\end{tabular}

Key:

\begin{tabular}{|l|l|l|l|}
\hline $\begin{array}{l}\text { Column } \\
\text { Reference: }\end{array}$ & Column & \\
\hline (a) $:$ & Project name identification & (e) $:$ & Lowest evaluated tender \\
\hline (b) $:$ & Year of commencement of project & (f) : & Difference between (d) and (e) \\
\hline (c) $:$ & $\begin{array}{l}\text { Categorisation by distances from } \\
\text { consultant's office }\end{array}$ & (g) : & Percentage difference of (f) \\
\hline (d) $:$ & $\begin{array}{l}\text { Quantity surveyor's preliminary } \\
\text { estimates }\end{array}$ & & \\
\hline
\end{tabular}




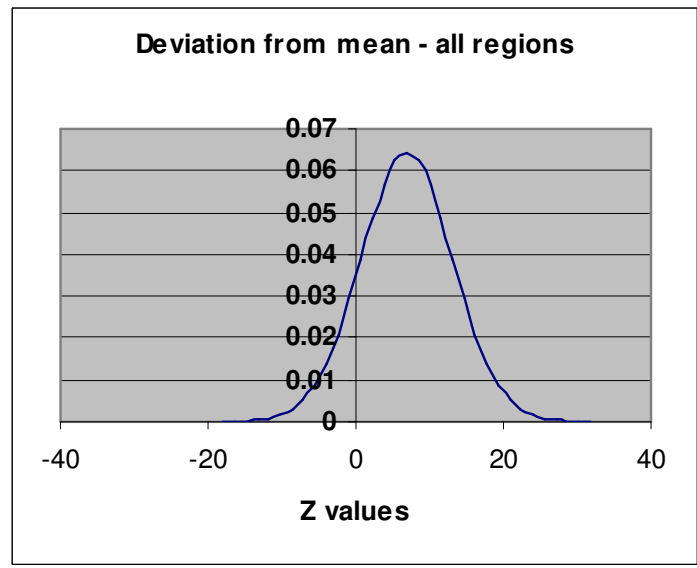

Figure III: Normal standard distribution curve of variance in all

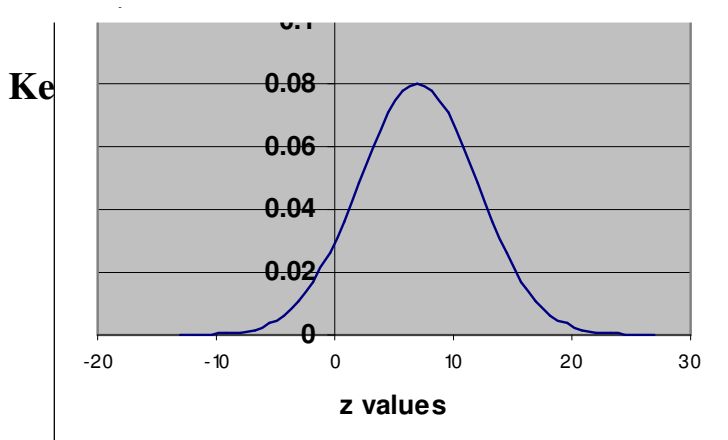

z-value: $\quad$ The standard deviation of each score away from the mean of 0 y- axis: $\quad$ Proportion of scores

Table 4: Variance between consultant's preliminary estimate and tender figure for projects at consultant base (Dar es Salaam city)

\begin{tabular}{|l|l|l|l|l|l|l|}
\hline Project & Year & Category & Preliminary cost estimates & Tender figure (US\$) & Variation & $\%$ \\
\hline & & & US \$ & US \$ & US \$ & \\
\hline I & 1996 & D & 741832 & 693301 & 48531 & 6,5 \\
\hline II & 1996 & D & 45423 & 41672 & 3751 & 8,3 \\
\hline III & 1996 & D & 20504 & 18725 & 1779 & 8,7 \\
\hline IV & 1996 & D & 226032 & 203632 & 22400 & 9,9 \\
\hline V & 1997 & D & 15469 & 14257 & 1212 & 7,8 \\
\hline VI & 1997 & D & 137946 & 126671 & 11274 & 8,2 \\
\hline VII & 1999 & D & 3715367 & 3396130 & 319236 & 8,6 \\
\hline VIII & 1999 & D & 13657061 & 12645426 & 1011635 & 7,4 \\
\hline IX & 1999 & D & 501355 & 455776 & 45578 & 9,1 \\
\hline X & 1999 & D & 61851 & 56692 & 5159 & 8,3 \\
\hline XI & 1999 & D & 6398 & 5924 & 474 & 7,4 \\
\hline CII & 1999 & D & 672797 & 625857 & 46939 & 7,0 \\
\hline XIII & 1999 & D & 908 & 825 & 83 & 9,1 \\
\hline XIV & 1999 & D & 140434 & 128249 & 12184 & 8,7 \\
\hline XV & 1999 & D & 627714 & 694642 & -66929 & $-10,7$ \\
\hline & & & & & \\
\cline { 2 - 6 } & & & Variation mean & & 7.0 \\
\hline & & Std dev & & 5.0 \\
\hline
\end{tabular}

\section{Analysis of Variance (ANOVA)}

In testing the statistical significance of the variances obtained among the categories established (refer table 2), an analysis of variance - single factor was adopted; and a null and alternative hypothesis were formulated.

\section{The null hypothesis:}

$\mathrm{H}_{\mathrm{o}}$ Geographical distance of project has no influence on the variance between the quantity surveyors preliminary estimates and the lowest evaluated tender; and

\section{The alternative hypothesis:}

$\mathrm{H}_{\mathrm{a}}$ : Geographical distance of project has an influence on the variance between the quantity surveyors preliminary estimates and the lowest evaluated tender

In the analysis, the categories were taken as the independent variables or factors and percentage variation between the quantity surveyors preliminary estimate and the lowest evaluated tender, the levels or the dependent variables (Refer table 5) 
Table 5: Established variances according to categorized geographical distances

\begin{tabular}{|c|c|c|c|c|c|c|c|c|c|c|c|c|c|c|c|c|c|c|}
\hline \multicolumn{3}{|c|}{ Categories } & \multicolumn{16}{|c|}{ VARIANCES FROM MEAN (\%) } \\
\hline & A & & $\begin{array}{l} \\
10,3\end{array}$ & 10,9 & $\begin{array}{l}- \\
10,5\end{array}$ & & - & - & & - & & - & - & - & - & - & 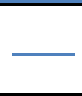 & \\
\hline & B & & 8,9 & 9,1 & 8,7 & 8,3 & 9,1 & 8,3 & 8,7 & 8,9 & $\begin{array}{l}- \\
11,1\end{array}$ & & & & & & & \\
\hline & $\mathrm{C}$ & & 9,1 & 7,4 & 6,3 & 9,1 & 7,8 & $\begin{array}{l} \\
1,5\end{array}$ & & & & & & $\longrightarrow$ & & & $\longrightarrow$ & \\
\hline- & D & - & 12,8 & 10,5 & 6,7 & 8,7 & 9,1 & 8,8 & 20,1 & 9,9 & 8,7 & 6,5 & 8,3 & 8,7 & 9,9 & 7,8 & 8,2 & 9,1 \\
\hline & $\mathrm{D}$ & & 8,6 & 7,4 & 9,1 & 8,3 & 7,4 & $\overline{7,0}$ & 9,1 & 8,7 & 10,7 & & & & & & & \\
\hline
\end{tabular}

Table 6 illustrates the results of a test of statistical significance of the variances amongst the categories (A, B, C, and D); whereby it is noted the "F ratio" has a value of
3.740 which is larger than the "F critical" of 2.845. This implies a statistical significance exists for the observed variances in the four categories.

Table 6: Analysis of variance for the various categories of sample

ANOVA: Single Factor

\section{SUMMARY}

\begin{tabular}{lllll}
\hline Groups & Count & Sum & Average & Variance \\
\hline A & 3 & -9.9 & -3.3 & 151.24 \\
B & 9 & 58.9 & 6.544444 & 43.86778 \\
C & 6 & 38.2 & 6.366667 & 15.99067 \\
D & 25 & 208.7 & 8.348 & 22.6376 \\
\hline
\end{tabular}

\begin{tabular}{lllllll} 
ANOVA & \multicolumn{1}{l}{} & & & & \\
\hline Source & of & & & & & \\
Variation & SS & df & MS & F & P-value & F crit \\
\hline Between Groups & 367.3671607 & 3 & 122.4557 & 3.740781 & 0.01869 & 2.845068 \\
Within Groups & 1276.677956 & 39 & 32.73533 & & & \\
& & & & & & \\
Total & 1644.045116 & 42 & & & & \\
\hline
\end{tabular}

\section{RESULTS AND DISCUSSIONS}

Results from Table 3 cover the full sample and show existence of variation between the Quantity surveyor's preliminary estimates and the lowest evaluated tender. The percentage variation is established by dividing the variation amount (refer Table 3 column (f)) by the quantity surveyor's preliminary estimates (refer Table 3 column (d)).

Such variation is noted to range from US $\$ 15,026^{1}$ showing the least variation, to US $\$ 122,948^{1}$ which is equivalent to $-11.1 \%$ to $+20.1 \%$ respectively.
The mean value of such variance is 6.9 and the standard deviation is 6.2 , which is viewed by the author to be on the high side. Taking this mean value as depicting the expected variation, this situation indicates values not being close to the 6.9 mean, implying, most preliminary estimates established by Quantity surveyors are far from the expected variation.

When a normal distribution curve is made from the data, it is observed that the theory of central tendencies exists; that the phenomenon is within the norm. The normal standard distribution curve indicates a greater population of the sample having higher $\mathrm{z}$ - values indicating a majority of samples deviating from the mean (refer figures III and IV). 
The sample for Dar es Salaam building projects however, (refer Table 4) shows a relatively lower standard deviation. This implies prediction of tender bids from preliminary estimates by quantity surveyors is relatively closer to the expected variation when the proposed projects are in close geographical vicinity to the one preparing the preliminary estimates. This is a justifiable situation as one expects geographical vicinity of the estimator and the project-building site, to enhance accuracy. One may inquire why this is so. It is presumed, for geographically closer sites, quantity surveyors are more conversant with site conditions and other important local information; hence make assumptions that are more realistic during the preliminary estimating process. The opposite is true for building projects that are far from the quantity surveyor's base; like for the study's sample, this refers to projects that are in the regions (refer Table 2 and Figure II). Furthermore, site visits during the preparation of preliminary estimates though essential, it is presumed by the author, for projects far from the Quantity surveyor's office, the probability for the consultant to make assumptions of site conditions is more likely than making a site visit. This is the other explanation for the outcome of Dar es Salaam projects as shown in Table 4.

The ANOVA test has further established variances that occur among the categories that reflect distances from the consultant firm and project location have a statistical significance. Hence the null hypothesis is rejected and the alternative adopted; that, geographical distance of project has an influence on the variance between the quantity surveyors preliminary estimates and the lowest evaluated tender

\section{CONCLUDING REMARKS}

The analysis has indicated that the Quantity surveyor's preliminary estimate figure is still far from the tender figure. Thus, its object of making the client aware of his financial obligations at the early stages of a building project is not met fully. A key remedy to this situation is for the quantity surveyor, the client and the design team to work together from the inception stage. Such a team approach will iron out the many assumptions that the quantity surveyor has to make during the preliminary estimate process; making the estimates rely on good quality and sufficient data showing findings that correspond to similar studies done in Singapore (Ling and See Boo, 2001).
With an increasing complexity of building projects, there is a need for practicing quantity surveyors to use an approach that enables the manipulation of numerous data and facilitate access and retrieval of data. The use of computer aided programs in the preliminary estimates could be a starting point and will give room for the quantity surveyor to focus on core issues that influence the estimate; such as gathering adequate physical data by making site visits.

Cost leadership has received differing emphasis by various authors (Haan et al, 2002; Langford and Male 2001). It is however viewed by the author that cost leadership is a core competence that gives construction organisations a superior position. With the traditional Building Procurement System dominance in Tanzania (Kamala and Hindle, 2000) and the existing link between the traditional procurement systems with the lowest price (Brown and Riley, 2000), cost leadership is a competence that organisations have to aspire for. Hence for as long as cost leadership continues to be a skill for core competence, quantity surveyors continue to face the challenge of producing preliminary estimates that are close to the lowest evaluated bid.

As a learning process in building projects, quantity surveying firms should make post-mortems or distil results from lessons of one project to another after tender action. For the client of building projects or procuring entities to obtain value for money when procuring quantity surveying services, there is a need to give priority to firms that are within the project locality. To operationalize such recommendations, geographical vicinity of a consultant in relation to the project can be added as amongst the criteria guiding selection by procuring entities or clients.

\section{REFERENCES}

Ashworth, A., (1999). Cost studies of buildings, $3^{\text {rd }}$ Edn., Addison Wesley Longman Ltd., Essex, England.

Bathurst, P. E., and Butler, D. A., (1980), $2^{\text {nd }}$ Edn., Building cost control techniques and economics, Heinemann, London.

Bless, C., and Higson-Smith, C., (1995), Fundamentals of Social Research Methods: An African perspective, $2^{\text {nd }}$ edn., Kenwyn Juta and Co Ltd, Cape town. 
Brown, D. C. and Riley, M. J., (2000), The application of BPR: A case study in construction, Knowledge and Process Management, Vol.7 (4), pp. 217- 223.

Cheung, F. K. T., and Skitmore, M., (2006), Applications of cross validation techniques for modelling construction costs during the very early design stage, Building and environment, Vol. 41 No. 12, pp. 1973-1990.

Dent, C., (1974), Construction cost appraisal: DCF techniques in the construction industry, George Godwin Limited, London.

Ferry, D. J., Brandon, P. S. B., and Ferry, J. D., (1991), $6^{\text {th }}$ Edn., Cost planning of Buildings, BSP Professional book, Oxford, London.

Flanagan, R., and Tate, B., (1997), Cost control in Building Design, Blackwell Science, Oxford.

Haan, J., Voordijk, H., and Joosten, G., (2002), Market strategies and core capabilities in the building industry, Construction Management and Economics, Vol. 20(2002), pp. 109 118.

MAGELAN Geographix (805) 6853100 from http://en.wikipedia.org/wiki/Tanzania retrieved on 5th July, 2007

Kamala, A. M., and Hindle, B., (2000), Forces of change and their impact on building procurement systems in use in Tanzania, Ed: Ngowi, A. B. and Ssegawa, J., Proc. $2^{\text {nd }}$ International conference on construction developing countries: challenges facing the construction industry in dusty in Developing countries, 15 -17 November 2000, Gaborone, pp. 421-430.

Langford, D., and Male, S., (2001), Strategic management in construction, $2^{\text {nd }}$ Ed., Blackwell Science, London.

Ling, Y. Y., and See Boo, J. H., (2001), Improving the accuracy estimates of building of approximate projects, Building Research \& Information, Vol. 29 No. 4, pp. 312-318.

Mongi, D. N., (1999), Study on application of approximate estimating techniques in Tanzania construction industry: (An evaluation between 1989- 1999), Unpublished dissertation,
University College of Lands \& Architectural Studies, Dar es Salaam.

Patton, M. Q., (1987), How to use qualitative methods in evaluation, SAGE Publications, California.

Seeley, I. H., (1981), Building economics: appraisal and control of building design cost and efficiency, $2^{\text {nd }}$ Edn., Macmillan, London.

Seeley, I. H., (1976), Building Maintenance, The Macmillan press Ltd., London.

Shen, Q., Fong, P. S. W., and Deng, M. Z. M., (2001), Developing an intelligent system for teaching pre-tender estimating of office building projects. John Wiley \& Sons Inc. p $26-35$.

Smith, J., and Love, P.E.D., (2000), Building Cost Planning in action, University Press, Geelong.

Sonmez, R., (2004), Conceptual cost estimation of building projects with regression analyisis and neural networks, Journal of Civil Engineering Vol.31, pp. 677-683.

Winch, G. M., and Carr, B., (2001), Process maps and protocols: understanding the shape of the construction process, Construction Management and Economics, Vol. 19, pp. $519-531$. 